Estudios Constitucionales, Año 17, No 1, 2019, pp. 87-118

ISSN 07180195

Centro de Estudios Constitucionales de Chile Universidad de Talca

"Las políticas estatales y los mecanismos de control frente a la expansión del derecho en

Argentina: La función del poder judicial según la Corte Suprema de Justicia (2005-2015)”

Alejo Joaquín Giles

\title{
LAS POLÍTICAS ESTATALES Y LOS MECANISMOS DE CONTROL FRENTE A LA EXPANSIÓN DEL DERECHO EN ARGENTINA: LA FUNCIÓN DEL PODER JUDICIAL SEGÚN LA CORTE SUPREMA DE JUSTICIA (2005-2015)*
}

\author{
THE STATE POLITICS AND THE CONTROL MECHANISMS IN THE FACE OF LAW \\ EXPANSION IN ARGENTINA: THE ROLE OF THE JUDICIARY ACCORDING TO \\ the Argentinian Supreme Court (2005-2015)
}

\author{
Alejo JoAQuín Giles ${ }^{* *}$ \\ Universidad Nacional de La Plata - Argentina \\ alejojgiles@gmail.com ${ }^{* * *}$
}

RESUMEN: El presente trabajo se inscribe en el problema general de la intersección entre los derechos, las politicas y los mecanismos de control. En particular, se centra en la respuesta que ha dado la Corte Suprema de Justicia argentina entre los años 2005 y 2015 a la interrogante sobre la función del poder judicial en el control de las politicas estatales necesarias para implementar los derechos constitucionales. La primera parte del trabajo (apartados I, II y III) dará cuenta de los presupuestos teóricos en los que el mismo se apoya: la expansión del derecho producida en Argentina a partir de la última reforma constitucional sobre aquello tradicionalmente reservado a la politica, y la dimensión institucional de esa ligazón, el control de la adecuación sustancial de las políticas a los objetivos sociales cristalizados como derechos. En la segunda parte del trabajo (apartados $I V y V$ ) se estudia la respuesta dada por el máximo tribunal argentino a la interrogante mencionada al comienzo. Allí se identifican las criticas más relevantes que suelen hacerse a ese tipo de respuestas y se presentan brevemente algunas alternativas que podrian mitigar esas criticas.

ABSTRACT: This work is enrolled in the general problem of the intersection between rights, policies and control mechanisms. In particular, it focuses on the answer given by the Argentinian Supreme Court between 2005 and 2015 to the question of the role of the Judiciary in controlling the state

\footnotetext{
* Trabajo recibido el 23 de abril de 2018 y aprobado el 17 de enero de 2019.

** El autor es abogado de la Universidad Nacional de La Plata (UNLP), máster en Razonamiento Probatorio por la Universitat de Girona y diplomado en Gestión y Control de Políticas Públicas por la Facultad Latinoamericana de Ciencias Sociales (flacso). Desempeña funciones en el Programa de Derechos Económicos, Sociales y Culturales de la Defensoría General de la Nación y como secretario de redacción de la Revista de Interés Público de la Facultad de Ciencias Jurídicas y Sociales de la Universidad Nacional de La Plata.

*** Este trabajo se ha enriquecido notablemente con las observaciones de quienes actuaron como evaluadores en el proceso de revisión para su publicación en esta revista. Les extiendo, entonces, mi reconocimiento y agradecimiento.
} 
policies necessary to implement constitutional rights. The first part of the work (sections I, II and III) will give an account of the theoretical budget's on which it is based: the expansion of the right produced in Argentina since the last constitutional reform on the matters traditionally reserved for politics; and the institutional dimension of that link, the control to the substantial adaptation of policies to social objectives crystallized as rights. In the second part of the paper (sections IV and V) it study the answer given by the Argentine Supreme Court to the question mentioned at the beginning. There it is identifies the most relevant criticisms that are usually made to this type of answers and it is briefly present some alternatives that could mitigate these criticisms.

Palabras ClaVE: politicas, politicas estatales, derechos, mecanismos de control.

KEY WORDS: policies, state policies, rights, control mechanisms.

\section{INTRODUCCIÓN}

A finales de los años 80 se desató en América Latina una oleada de reformas constitucionales. A través de ellas, la mayoría de los países de este lado del mundo reformularon, con distinta amplitud y alcances, delicados aspectos de sus pactos políticos.

Uno de los factores comunes de esas reformas, apuntan los comparatistas, es la ampliación dogmática de los textos constitucionales. Se incorporaron a modelos constitucionales - predominantemente- liberales una serie de derechos enfocados en el acceso a ciertos bienes considerados necesarios para que las personas puedan subsistir y desarrollarse dignamente ${ }^{1}$.

La Constitución mexicana de 1917 fue pionera en la ruptura con la impronta liberal de los textos constitucionales de la región, al incorporar al catálogo de derechos de libertad una serie de derechos enfocados en las condiciones materiales en las que se desarrolla la vida de las personas. Luego de ese hito, la mayoría de los Estados latinoamericanos han incorporado a sus textos fundamentales cláusulas de tal calibre.

Ese rasgo de nuestro constitucionalismo reciente es uno de los factores conglomerantes más fuertes entre las reformas de las últimas décadas. A tal punto que muchos autores se refieren a esa oleada como constitucionalismo social latinoamericano, precisamente por los cambios en el contenido dogmático de los nuevos textos constitucionales en comparación con los anteriores, de tradición liberal.

\footnotetext{
1 Puede encontrarse un análisis sistemático y comparativo del contenido general de estas reformas en UPRIMNY (2011). Un breve panorama del constitucionalismo latinoamericano nos muestra que hasta promediar el sigo XX imperó en nuestras constituciones una impronta liberal-conservadora, caracterizada por conjugar ciertos rasgos de perfeccionismo moral con un esfuerzo predominantemente por resguardar a las personas de las inmisiones del Estado en sus vidas [véase Gargarella (2014)].
} 
Las nuevas constituciones, afirman algunos, han abierto lugar a órdenes jurídicos comprometidos con la justicia social o distributiva.

$\mathrm{Al}$ fragor de estas reformas han pasado a considerarse como derechos, entre otros, el acceso a la seguridad social, a la asistencia sanitaria, a la educación, a la alimentación y a la vivienda. Si bien no puede decirse que el origen del reconocimiento de tales derechos se ubica recién a finales de siglo (el ejemplo mexicano desmentiría una afirmación de ese tipo), sí puede sostenerse que la consagración de los mismos ha sido incrementada -cualitativa y cuantitativamente- en las constituciones de la región a partir de ese momento.

Muchos Estados, a la vez, se han declarado pluriétnicos y pluriculturales, en tanto promueven (y no desalientan) la diversidad. Por otra parte, también se incluyeron preceptos acerca de la relación entre el ser humano y el ecosistema en que habita. Es así que las constituciones han reconocido, a través de fórmulas múltiples, una serie de derechos relacionados con la conservación del ambiente y la prevención de los daños que los proyectos de desarrollo pudieran ocasionarle.

Estamos ante pactos políticos que tienen un carácter transformador: ${ }^{2}$ están preconcebidos para producir cambios sociales en el sentido estipulado por el contenido de los derechos que reconocen ${ }^{3}$.

Las constituciones liberales en cierto sentido también lo eran, pues a la par que cristalizaban relaciones sociales, también sentaban las bases para desarrollar determinados proyectos políticos. Lo que distingue a unas de otras, entonces, no es el carácter transformador en sí mismo, sino el sentido -y quizá la magnitud- de la transformación buscada. Mientras en los sistemas políticos modernos se afirma la irrelevancia política de la desigualdad social y la pobreza ${ }^{4}$, los nuevos textos constitucionales hacen que la desigualdad y la pobreza ya no puedan resultar indiferentes para las organizaciones estatales.

2 Sobre el carácter transformador del nuevo constitucionalismo, véase SANTOS (2010), pp. 71 y ss. En similar sentido, R. UPRIMNY apunta que la mayor parte de las reformas constitucionales latinoamericanas son documentos que tienden a delinear un modelo de sociedad a construir, en vez de codificar las relaciones de poder existentes [UPrimny (2011), p. 123].

3 Las maneras de definir ese contenido son un problema en sí mismo, que ocupa buena parte de los debates de la teoría constitucional contemporánea. Algunos dicen, por ejemplo, que el sentido concreto de los derechos constitucionales -o su contenido- puede definirse mediante leyes y, ante su ausencia, insuficiencia o irrazonabilidad, por la interpretación judicial. Pese a su importancia, no abordaré en detalle este problema en esta oportunidad, pues mi centro de atención es otro. Sobre la cuestión de la interpretación constitucional enfocada en derechos sociales, véase ETCHICHURY (2013), pp. 145 y ss.

4 Capella (1999), p. 145. 
Argentina ha participado de esa oleada con la reforma constitucional de 1994. Algunos nuevos derechos fueron incluidos en el texto de la constitución reformada (como el derecho a un ambiente sano), mientras que otros -la mayoría- fueron incorporados al dotar de jerarquía constitucional a numerosos instrumentos internacionales de derechos humanos, como la Convención Americana de Derechos Humanos y el Pacto Internacional de Derechos Económicos, Sociales y Culturales.

El texto constitucional argentino y las constituciones latinoamericanas reformadas en la oleada iniciada a fines del siglo XX comparten dos características atribuidas al neoconstitucionalismo: por un lado, el reforzamiento de su carácter valorativo, pues consagran un orden de valores que debe ser aplicado y realizado, y por el otro, el fortalecimiento del valor normativo del derecho que emana de ellas, en tanto se las concibe no solo como un simple documento político, sino como una norma que vincula especialmente a todas las autoridades estatales ${ }^{5}$.

El fenómeno al que vengo refiriendo tiene múltiples efectos y abre también numerosos interrogantes.

Aquí me ocuparé de analizar la respuesta que ha dado la Corte Suprema de Justicia argentina, en su integración entre los años 2005 y 2015, a uno de ellos: ¿cuál es la función que le cabe al poder judicial en el control de las políticas estatales necesarias para implementar los derechos constitucionales?

En esa línea, también me referiré a las críticas más relevantes que suelen hacerse a esa clase de respuestas y presentaré algunas alternativas que podrían mitigar esas críticas.

Pero antes me permitiré señalar los presupuestos teóricos que le dan sentido a dicha pregunta, que en parte ya han sido presentados.

El primer presupuesto es la existencia de una estrecha vinculación entre los derechos y las políticas estatales. ¿Qué relación puede trazarse entre los nuevos derechos y las políticas estatales? ¿Es problemático que las políticas nieguen o simplemente no activen derechos?

El segundo presupuesto tiene que ver con la dimensión institucional de esa ligazón. ¿Con qué herramientas institucionales cuenta el Estado argentino para resolver los supuestos de falta de acople entre las políticas estatales y el contenido de los derechos?

Esta última interrogante se afinca en las capacidades del Estado para garantizar dicho acople, entendiendo la noción de capacidad estatal como "la aptitud de las

5 Comanducci (2007), pp. 73 y ss. 
instancias de gobierno para plasmar, a través de políticas públicas, los máximos niveles posibles de valor social" (Repetto, 2004, p. 8) ${ }^{6}$.

\section{El PRINCIPIO ACTIVO: EXPANSIÓN DEL DERECHO Y POLÍTICAS ESTATALES}

Al ampliar el catálogo de circunstancias de la vida que son relevantes jurídicamente, la última reforma constitucional en Argentina ha expandido el campo del derecho, transfiriendo mayores cuotas de poder a quienes se encargan de decir cuáles son los alcances y significados del derecho en la sociedad ${ }^{7}$. Mientras más circunstancias y/o eventos de la vida social son presupuestos o condiciones de aplicación del derecho, mayores resultan las atribuciones y poderes de quienes se encargan de dirimir (en virtud de determinada distribución de las funciones sociales) los conflictos jurídicos.

Esto incide sobre el campo de la política, dado que genera superposiciones de competencias acerca de aquellas cuestiones que, tradicionalmente libradas a ella, han pasado a ser abarcadas por el contenido (relativamente indeterminado) de los derechos. Tal intersección es el principio activo del presente trabajo.

Entiendo que esa expansión ha significado una redefinición de los fines y funciones de la organización estatal. El Estado ha pasado a ser concebido como una herramienta primordial para la concreción del contenido de los nuevos derechos. A diferencia de los derechos civiles y políticos, explica Boaventura de Sousa Santos, los derechos económicos y sociales.

Implican prestaciones del Estado, presuponen su cooperación activa y deciden una lucha politica por la apropiación social del excedente capturado por el Estado mediante impuestos

6 Todo análisis de capacidades estatales tiene una dimensión institucional. Como explica RePETTO (2004), "[l] as instituciones constituyen un aspecto central en la construcción de la 'capacidad estatal' bajo el prisma de los ciclos de políticas públicas, ya sea para identificar problemas, sea para diseñar y gestionar una política pública con la participación de multiplicidad de actores. En el seno de ella, es la interacción institucionalizada la que debe marcar el tono y el contenido del proceso" (p. 10). Desde esa perspectiva, "el marco institucional permitirá entender la estructura de oportunidades que enfrentan los individuos y los grupos al interactuar, guiados por identidades propias. Asimismo facilitará la comprensión de las potenciales rutas de acceso, por donde se canalicen las demandas y necesidades de los distintos sectores que conforman el espacio público" (p. 11).

7 Recurro aquí -y lo haré en adelante- a la noción de campos sociales (y a la de campo del derecho como uno de ellos) propuesta por el sociólogo francés Pierre Bourdieu (2001). 
y otras fuentes de ingresos. La efectividad de esos derechos humanos depende totalmente de Estado y, por tanto, implica una transformación de la naturaleza politica de su acción ${ }^{8}$.

La relación de los ciudadanos con el Estado, que bajo el prisma liberal se configuraba como una garantía de separación, ahora ha sido ensanchada y reformulada. La impronta transformadora del nuevo orden jurídico coloca a los ciudadanos en condiciones de exigirle al Estado que garantice ciertas condiciones mínimas de vida y a este último en la obligación de echar a andar las capacidades de ingeniería social que detenta para pergeñar el orden social buscado. Esas capacidades les permiten a las organizaciones estatales promover determinadas relaciones y desincentivar otras (acentuadas o disminuidas según el modelo de Estado imperante), favoreciendo u obstaculizando el logro de determinados objetivos. La incorporación de derechos sociales a los pactos políticos ha redefinido esos objetivos y, en consecuencia, trae consigo un cuestionamiento general a la capacidad de las instituciones tradicionales - pensadas y diseñadas a través de un prisma liberal- para asegurar -como deben hacerlo- la vigencia sociológica de los nuevos preceptos.

Subyace a estas afirmaciones la idea de que las posibilidades de los nuevos derechos de adquirir vigencia sociológica -y convertirse en experiencias vitalesestán fuertemente determinadas por la estructura institucional disponible para hacer efectivos los cambios sociales requeridos por ellos. Para expandir los derechos sociales, se sostiene, resulta imprescindible abandonar la pulsión antiestatal propia de la teoría liberal de los derechos humanos ${ }^{9}$, y dedicar las energías creativas a significar la relación entre los nuevos derechos y las acciones del Estado.

Esto coloca a las políticas estatales en un primer plano, ya que son nada menos que la expresión de la potencia transformadora de la estatalidad que le permite operar sobre la brecha entre los derechos y la realidad. Se hablará de ellas en el sentido pincelado por O. Oszlak y G. O’Donnell (1995), como aquel "conjunto de acciones y omisiones que manifiestan una determinada modalidad de intervención del Estado en relación con una cuestión que concita la atención, interés o movilización de otros actores de la sociedad civil” (pp. 112-113).

De esa noción me interesa extraer dos notas características, sobre las que volveré luego. Por un lado, que toda política estatal implica una toma de posición predominante sobre determinada cuestión, manifestada a través de una decisión o

8 SANTOS (2014), p. 44.

9 SAntos (2014). 
un conjunto de ellas que denotan, con un sentido normativo, el modo en el que el Estado pretende intervenir ante tales demandas.

[L]a politica estatal no constituye ni un acto reflejo ni una respuesta aislada, sino más bien un conjunto de iniciativas y respuestas, manifiestas o implicitas, que observadas en un momento histórico y en un contexto determinados permiten inferir la posición -agregaríamos, predominante- del Estado frente a una cuestión que atañe a sectores significativos de la sociedad ${ }^{10}$.

De acuerdo con ello, pequeñas decisiones individuales pueden llegar a denotar políticas estatales siempre que se repliquen y permitan inferir cierta generalidad en el criterio adoptado (o una disposición de aplicación universal del mismo). Identificar políticas estatales entre un conjunto de decisiones requerirá, entonces, de razonamientos inductivos.

Por otro lado, señalan los autores citados que dichos posicionamientos no suceden en abstracto: están motivados por ciertas demandas que logran introducirse como cuestiones en la agenda pública. Y esa introducción no sucede per se, sino que responde a la capacidad de ciertos actores sociales (en virtud de su capital político) para influir en esa agenda e introducir sus necesidades y demandas (en exclusión de otras no problematizadas). El objeto y la finalidad de la política surgirán de esa problematización, y responderán a las características de las condiciones de su surgimiento ${ }^{11}$.

En mi opinión, una adecuada significación del valor normativo del derecho emanado de la Constitución coloca a los derechos como un factor coadyuvante en la formación de las cuestiones sobre las que el Estado debe decidir e, inclusive, sobre el contenido de esa decisión.

El Estado se encuentra doblemente obligado en relación con los derechos: por un lado, tiene vedado decidir intervenir en su desmedro y, por el otro, está compelido a entablar políticas que persigan las transformaciones necesarias para su completa vigencia de un modo progresivo ${ }^{12}$.

Desde esa perspectiva, las políticas se encuentran limitadas y dirigidas por el contenido de los derechos que deben transformar en realidades. Según la Corte

10 Oszlak y O’Donnell (1995), p. 113.

11 Oszlak y O’Donnell (1995), p. 110.

12 Abramovich (2006), pp. 14, 25; Pérez, Rodríguez y Uprimny (2007), p. 19. Para un análisis detallado del principio progresividad y no regresividad en los niveles de protección de los derechos humanos, véase Courtis (2006). 
Suprema argentina, "[l]as políticas tienen un marco constitucional que no pueden exceder, que son las garantías que señala la Constitución y que amparan a todos los habitantes de la Nación"13.

Si partimos de que el plexo normativo constitucional se encuentra supraordenado respecto a las demás normas y actos estatales (en tanto los condiciona con su contenido), y contiene pretensiones de cambio social que solo pueden ser logradas a través de la actividad del aparato estatal, los lineamientos y la ejecución de dicha actividad no pueden quedar totalmente librados al arbitrio de las autoridades ejecutivas. Al contrario, están constitucionalmente condicionados. Aceptar la pasividad estatal como una opción exenta de reproche implicaría reducir a cero el valor normativo de los nuevos derechos, consolidando a la vez la irrelevancia práctica de los pactos políticos volcados en constituciones.

\section{AdECUACIÓN SUSTANCIAL Y MECANISMOS DE CONTROL}

El vínculo trazado entre derechos y políticas nos lleva a interesarnos por una cuestión institucional: ¿qué tipo de respuestas debe dar el entramado institucional cuando las políticas niegan o simplemente no activan derechos? ¿Con qué herramientas cuenta el Estado argentino para resolver tales situaciones?

La importancia de la pregunta va de suyo. En su respuesta se pone en juego la potencia performativa del texto constitucional; es decir, su capacidad para traducir en hechos las declaraciones que contiene.

Por eso, uno de los presupuestos teóricos de este trabajo tiene que ver con la ligazón institucional de esa relación entre derechos y políticas. En especial, con las capacidades institucionales del Estado para garantizar que las políticas estatales se desarrollen de conformidad con el contenido de los derechos o, en otras palabras, que sean sustancialmente adecuadas (expresión que utilizaremos en adelante para referir a dicha situación de correlación).

Si se acepta que, como se acaba de afirmar, el vínculo entre políticas y derechos resulta imprescindible para que sucedan los cambios sociales promovidos por estos, si es solo a través de la actividad estatal que se pueden convertir en hechos, entonces se vuelve imperioso concentrarnos en los modos de asegurar que esa actividad suceda. Que esa actividad suceda se vuelve un problema con relevancia jurídica de primera gravitación institucional.

13 CSJN, "Recurso de hecho deducido por el Centro de Estudios Legales y Sociales en la causa Verbitsky, Horacio s/ habeas corpus", Fallos 328:1146, de 3 de mayo de 2005, considerando 27. 
Sobre esa plataforma entiendo que vale la pena adoptar una perspectiva de las capacidades institucionales del Estado, destacando la relevancia de contar con herramientas o dispositivos que tengan por función garantizar la sustancial adecuación entre las políticas y los objetivos trazados por los derechos, de modo que aquellas contribuyan a lograr progresivamente la plena efectividad de los derechos humanos, como lo manda, entre otros instrumentos, la Convención Americana de Derechos Humanos (art. 26).

Al momento de evaluar la capacidad estatal para honrar esos compromisos, la presencia de herramientas destinadas a operar en la brecha entre los derechos y las políticas que deben darles vigencia resulta de primera relevancia.

La significancia del dato institucional para el logro progresivo de los derechos ha sido ponderada por la Comisión Interamericana de Derechos Humanos al definir los "Lineamientos para la elaboración de indicadores de progreso en materia de derechos económicos, sociales y culturales" (OEA/Ser.L/V/II.132), que se utilizan para medir el grado de cumplimiento de los compromisos en esa materia adoptados por los Estados americanos firmantes del "Protocolo de San Salvador", adicional a la Convención Americana sobre Derechos Humanos ${ }^{14}$.

Según aquel organismo internacional, resulta relevante "la información sobre los factores estructurales que determinan la posibilidad de acceso efectivo a los derechos sociales" (párr. 17).

Asi, por ejemplo, los indicadores de derechos asignan un lugar muy importante a la forma de reconocimiento constitucional y legal de los derechos en cada pais, a los mecanismos de participación, de transparencia y de rendición de cuentas disponibles; al diseño institucional de las políticas, los programas y servicios sociales que organiza el Estado para realizar los derechos [...] y al funcionamiento de los sistemas de justicia, entre otros aspectos (párr. 17).

Entre esa información, entiende que es necesario "medir la capacidad de las personas de exigir los derechos de los que son titulares", lo que "no depende sólo del reconocimiento normativo, ni de la posición legal de cada individuo, sino de la disponibilidad de una serie de recursos y capacidades" (párr. 18).

${ }_{14}$ El Protocolo Adicional a la Convención Americana sobre Derechos Humanos en Materia de Derechos Económicos, Sociales y Culturales, denominado "Protocolo de San Salvador", establece el deber de los Estados parte de enviar a la Organización de los Estados Americanos informes periódicos respecto de medidas progresivas que hayan adoptado para asegurar el debido respeto de los derechos comprometidos (art. 19). En ese marco, la Comisión Interamericana de Derechos Humanos ha estipulado unos lineamientos para la elaboración de indicadores de progreso del cumplimiento de los Estados de esos compromisos. 
Partiendo de esas consideraciones, el organismo propone que una de las categorías utilizadas para organizar la información requerida a los firmantes del Protocolo se refiera a las capacidades estatales. Esa categoría "describe un aspecto técnico instrumental y de distribución de recursos de poder al interior del aparato estatal", lo cual supone "revisar de qué manera y bajo qué parámetros el Estado (y sus diversos poderes y reparticiones) resuelven el conjunto de cuestiones socialmente problematizadas" (párr. 38) ${ }^{15}$.

Entre los distintos aspectos que integran esa categoría, la comisión destaca especialmente "la existencia de organismos de control, monitoreo y evaluación de los programas y servicios sociales dentro de la estructura estatal” (párr. 40).

La perspectiva sostenida en este trabajo se ubica en esa línea. Frente a la eventual disociación entre los objetivos cristalizados como derechos y las políticas estatales, se considera vital para el logro de las transformaciones buscadas por la Constitución el contar con mecanismos institucionales de control de la adecuación sustancial entre ambos factores. Sobre tal plataforma es que se analiza luego la función asignada al poder judicial en torno a ello por la Corte Suprema de Justicia de la Nación argentina en su integración entre los años 2005 y 2015.

Pese a lo dicho, si prestamos atención al entramado orgánico del Estado argentino a nivel nacional, podremos ver que no se dispone de mecanismos dedicados exclusivamente a esa tarea. En el apartado siguiente veremos, desde la perspectiva de la corte, en qué medida el poder judicial podría llenar ese vacío. Pero antes les propongo hacer un breve paneo sobre los mecanismos de control previstos a nivel nacional, para que podamos advertir la vacancia que el máximo tribunal argentino propone llenar.

A nivel nacional, los mecanismos de control del sector público están previstos en la Ley No 24.156. Tienen la función de asegurar que, en los procesos de obtención y aplicación de recursos públicos, la administración pública nacional se rija por los principios de regularidad financiera, legalidad, economicidad, eficiencia y eficacia (art. 4o a). Es evidente su relevancia para la ejecución de políticas estatales: aquellas formas y principios que hayan de regir a la administración en la

15 Para la comisión, medir las capacidades estatales también "[i]mplica analizar las reglas de juego al interior del aparato estatal, las relaciones interinstitucionales, la división de tareas, la capacidad financiera y las habilidades del recurso humano que tiene que llevar adelante las tareas definidas. A modo de ejemplo, un indicador estructural de capacidad estatal es la existencia de agencias específicas dentro del Estado destinadas a la protección o implementación de un derecho social. También puede usar un indicador estructural para indagar sobre sus competencias y funciones" (párr. 38). 
obtención y administración de recursos se erigen, a la vez, como el marco formal que ha de regir la ejecución de tales políticas.

La norma concibe, por un lado, un sistema de administración financiera, comprendido por el "conjunto de sistemas, órganos, normas y procedimientos administrativos que hacen posible la obtención de los recursos públicos y su aplicación para el cumplimiento de los objetivos del Estado" (art. 2º). Y, por el otro, crea dos sistemas de control: uno de control interno y otro de control externo.

El primer sistema de control está a cargo de la Sindicatura General de la Nación (Sigen), una entidad dependiente del poder ejecutivo nacional que tiene la función de prestar a la estructura administrativa nacional el servicio de auditoría interna, descripto por la ley como "un examen posterior de las actividades financieras y administrativas de las entidades a que hace referencia esta ley, realizada por los auditores integrantes de las unidades de auditoria interna” (art. 102).

El segundo sistema está a cargo de la Auditoría General de la Nación (AGN), que realiza el control externo de los actos de la administración; es decir, se trata de un órgano autónomo de la estructura administrativa central que la controla. La Constitución Nacional le destina el ejercicio del "control de legalidad, gestión y auditoría de toda la actividad de la administración pública centralizada y descentralizada, cualquiera fuera su modalidad de organización” (art. 85). La Ley No 24.156 le otorga competencia para ejercer "el control externo posterior de la gestión presupuestaria, económica, financiera, patrimonial, legal, así como el dictamen sobre los estados contables financieros de la administración" (art. 117).

En síntesis, tales organismos analizan el modo en que la autoridad estatal administra los recursos públicos, con el afán de promover la economía, la transparencia, la eficiencia y la eficacia en el uso de los mismos. Pero omiten controlar la adecuación sustancial de las políticas estatales, es decir, resolver las situaciones de falta de correlación de las que se dio cuenta antes.

Los mecanismos disponibles se limitan a correr detrás de las decisiones administrativas procurando que se ejecuten legalmente, pero no se colocan frente a ellas, para observar su corrección desde un enfoque de derechos. Mientras se analiza - por ejemplo- que las partidas presupuestarias se ajusten a una determinada planificación o asignación, no se prevé trazar un vínculo entre dichas decisiones y los objetivos que constitucionalmente tiene que cumplir el Estado en virtud de los derechos que hubiera consagrado.

Pero ese vacío, como veremos, también puede ser considerado como un campo de acción. 


\section{UnA RESPUESTA ANTE EL VACÍO: El CONTROL JUdiCial DE LAS POlÍticas estatales según la Corte Suprema de Justicia de la Nación}

La resolución del problema sobre el que surcan estas líneas se ha trasladado en buena medida a los tribunales. Consolidada la reforma constitucional, una de las problemáticas que surgieron con mayor evidencia en el campo del derecho tiene que ver con las situaciones de falta de correlación de las que hablamos aquí: las experiencias vitales de las personas distaban mucho $-y$ lo hacen- del contenido de los nuevos derechos.

Ello llevó a sus actores (abogados, doctrinarios, funcionarios judiciales) a preguntarse: ¿puede ser exigido el cumplimiento de esos derechos?, ¿podemos utilizar con ellos los mismos mecanismos de garantía que venimos usando para los "derechos de libertad"?

Así es que la judicatura entra en la escena del control de políticas estatales. Si los derechos abordan cuestiones del campo de la política, ¿cuál es el papel que juega el poder judicial en todo eso?

Ese relato, como resulta evidente, es una ilustración de un camino de arduo, recorrido que aún hoy continúa surcándose.

En lo que sigue analizaré las respuestas que ha dado la Corte Suprema de Justicia de la Nación argentina (CSJN), entre los años 2005 y 2015, a esa interrogante. Alterando considerablemente su tradicional doctrina de las cuestiones politicas no justiciables, la corte ha fijado una posición sobre el tema que nos ocupa ${ }^{16}$.

Si bien esas decisiones no nos permiten reconstruir un posicionamiento general sobre ese tópico en la jurisprudencia argentina, la ubicación institucional de su emisora y el poder de influencia que eso le confiere, las vuelve especialmente relevantes para los demás jueces y juezas, en particular al momento de sentenciar en un caso donde esté en juego la falta de acople entre las políticas estatales y los derechos.

Vale aquí una aclaración. Argentina no tiene un sistema de precedentes obligatorios, es decir que no hay fallos de la Corte Suprema que técnicamente deban ser seguidos por los tribunales inferiores. Pero el tribunal ha sostenido en su

16 Las orientaciones que contienen estas sentencias no son exclusivas del máximo tribunal argentino, sino que se han replicado en algunos de los países latinoamericanos que reformaron sus constituciones recientemente. Eso nos podría llevar a pensar que tales reformas son el principio activo de una problemática común acerca del control sustancial de políticas estatales. A modo de ejemplo, puede verse el desarrollo de estos argumentos en la sentencia T-025 de 2004 de la Corte Constitucional de Colombia, que versa sobre los desplazamientos forzados en ese país y la omisión del Estado colombiano de articular políticas que impidan la violación sistemática a los derechos humanos producida por esa problemática. 
jurisprudencia que existe lo que ha llamado un deber moral de seguimiento de sus sentencias, en virtud del cual los jueces y tribunales inferiores tienden a replicar los criterios adoptados por dicho órgano. Más recientemente, en una sentencia de marzo de 2018 ("Viñas", Fallos: 341:570), la corte ha sostenido que la autoridad institucional de sus precedentes da lugar a que, cuando los tribunales inferiores decidan en casos sustancialmente análogos, consideren debidamente y sigan las conclusiones que el máximo tribunal hubiera adoptado.

Del conjunto de sentencias que veremos a continuación quedará en evidencia la decisión de la Corte Suprema, en su integración hasta 2015, de adjudicar al poder judicial ciertas facultades de evaluación y control sobre las políticas estatales. Eso redunda en una maximización del capital específico del campo del derecho y, por consiguiente, en un aumento de poder para quienes en él tienen el monopolio de decir qué es el derecho (Bourdieu, 2001, p. 186).

Las sentencias han sido seleccionadas del repositorio del máximo tribunal argentino siguiendo dos criterios. Uno es temporal: las dictadas entre los años 2005 y 2015. En ese período ya se había producido la reforma constitucional de 1994 y la integración del tribunal se mantuvo relativamente estable, con los jueces Fayt (1983-2015), Petracci (1983-2014), Maqueda (2002), Zaffaroni (2003-2014), Highton de Nolasco (2004), Argibay (2005-2014) y Lorenzetti (2005). Eso cambió a poco de que la integración cumpliera una década. En el año 2014, se jubiló el juez Zaffaroni y fallecieron la jueza Argibay y el juez Petracci. En el año 2015 falleció el juez Fayt. En el año 2016 asumieron los jueces Rosatti y Rosenkrantz. Actualmente, el tribunal está integrado por cinco miembros: Maqueda, Highton de Nolasco, Lorenzetti, Rosatti y Rosenkrantz.

El otro criterio de selección es temático: las sentencias que se refieran expresamente al control judicial de las políticas públicas. En el repositorio del máximo tribunal recurrí a una serie de palabras clave ${ }^{17}$ y filtré los resultados por el thema decidendum: la constitucionalidad de una política pública.

La primera vez que el tribunal se expidió con detalle sobre el modo de resolver el problema de acople que nos ocupa fue en la decisión del caso "Verbitsky" en $2005^{18}$.

\footnotetext{
17 A saber: "poder judicial”; "jueces”; "control judicial”; "constitución nacional”; "derechos de incidencia colectiva"; "control de constitucionalidad"; "constitución nacional”; "cuestiones políticas"; "caso o controversia"; "políticas públicas"; "principio de progresividad"; "contaminación".

18 CSJN, "Recurso de hecho deducido por el Centro de Estudios Legales y Sociales en la causa Verbitsky, Horacio s/ habeas corpus", Fallos 328:1146, de 3 de mayo de 2005.
} 
En esa ocasión intervino en un habeas corpus colectivo en el que se cuestionaba nada menos que la política penitenciaria de la provincia de Buenos Aires (la más extensa y poblada de Argentina). Como lo denunciaban los actores, encontró que las deplorables condiciones de higiene y seguridad en que vivían -y vivenlas personas detenidas contrariaban -y contrarían- sus derechos fundamentales.

En consecuencia, ordenó una serie de medidas para remediar la lamentable situación de las cárceles provinciales. Entre ellas: hacer cesar la detención en comisarías de personas menores de edad y enfermas; instruir a los órganos jurisdiccionales provinciales que hicieran cesar inmediatamente todas las situaciones que importen un trato cruel, inhumano o degradante (y ordenar al ejecutivo que les remita un informe detallado de la situación en que se encuentran las personas privadas de libertad), y disponer que el ejecutivo le informe bimestralmente las medidas adoptadas para mejorar la situación de todos los detenidos.

Para así decidir, antes se hizo cargo del discurso que niega atribuciones al poder judicial para analizar la actividad política. Dijo:

[A] diferencia de la evaluación de politicas, cuestión claramente no judiciable, corresponde sin duda alguna al Poder Judicial de la Nación garantizar la eficacia de los derechos, y evitar que éstos sean vulnerados, como objetivo fundamental y rector a la hora de administrar justicia y decidir las controversias.

Ambas materias se superponen parcialmente cuando una política es lesiva de derechos, por lo cual siempre se argumenta en contra de la jurisdicción, alegando que en tales supuestos media una injerencia indebida del Poder Judicial en la política, cuando en realidad, lo único que hace el Poder Judicial, en su respectivo ámbito de competencia y con la prudencia debida en cada caso, es tutelar los derechos e invalidar esa política sólo en la medida en que los lesiona. Las politicas tienen un marco constitucional que no pueden exceder, que son las garantías que señala la Constitución y que amparan a todos los habitantes de la Nación; es verdad que los jueces limitan y valoran la politica, pero sólo en la medida en que excede ese marco y como parte del deber especifico del Poder Judicial. Desconocer esta premisa sería equivalente a neutralizar cualquier eficacia del control de constitucionalidad (considerando 270).

En el fallo "Gutiérrez"19, de 2015, la corte ratificó con ahínco esa tesis al decidir un habeas corpus colectivo en el que se discutía dos aspectos de la política penitenciaria del Servicio Penitenciario Federal: la inexistencia de un sistema de

19 "Recurso de hecho deducido por el Defensor Oficial de Alejandro Gutiérrez en la causa Gutiérrez, Alejandro s/ causa No 11.960", Fallos: 338:68, de 19 de febrero de 2015. 
seguridad adecuado para cumplir satisfactoriamente con los traslados diarios de los internos, y las medidas de castigo consistentes en el encierro en celdas cuya apertura demora un tiempo excesivo y que impide su atención inmediata en casos de urgencia. La Cámara de Casación había sostenido que las decisiones de diseño y seguridad carcelaria son privativas del poder ejecutivo y, por consiguiente, ajenas al poder judicial. La corte respondió a ello citando el fragmento aquí transcripto del precedente "Verbitsky".

A eso agregó esta importante consideración: en algunos casos -como en el que estaba decidiendo- el cese de una situación irregular violatoria de derechos

[...] puede no alcanzarse mediante el mero requerimiento a las autoridades para que se abstengan de realizar una conducta sino que, por el contrario, para poner fin a este estado de cosas, también puede resultar necesario exigir la adopción, por parte de las autoridades penitenciarias, de conductas positivas de realizar reformas sistemáticas (considerando $7^{\circ}$ ).

En "Defensor del Pueblo contra Chaco"20, de 2007, el tribunal intervino frente a una demanda colectiva interpuesta por el Defensor del Pueblo de la Nación contra el Estado nacional y la provincia de Chaco por las condiciones de vida (salud, alimentación, vivienda, educación, entre otras) de una serie de personas pertenecientes a la etnia toba. Demostró el defensor que el grupo se encontraba en una situación de emergencia extrema que hacía peligrar la vida de sus integrantes. En virtud de esa situación, la corte ordenó como medida cautelar el urgente suministro de agua potable y alimentación a la comunidad afectada y la provisión de medios de transporte hacia los establecimientos sanitarios cercanos. Justificó dicha disposición así:

Que la gravedad y urgencia de los hechos que se denuncian exigen de esta Corte el ejercicio del control encomendado a la justicia sobre las actividades de los otros poderes del Estado y, en ese marco, la adopción de las medidas conducentes que, sin menoscabar las atribuciones de estos últimos, tiendan a sostener la observancia de la Constitución Nacional [...]. Ello es así, pues le corresponde al Poder Judicial de la Nación buscar los caminos que permitan garantizar la eficacia de los derechos, y evitar que estos sean vulnerados [...]. No debe verse en ello una intromisión indebida del Poder Judicial cuando lo único que se hace es tender a tutelar derechos, o suplir omisiones en la medida en que dichos derechos puedan estar lesionados (considerando $3^{\circ}$ ).

20 CSJN, "Defensor del Pueblo de la Nación c/ Estado Nacional y otra (Provincia del Chaco) s/ proceso de conocimiento", Fallos 330:4134, de 18 de septiembre de 2007. 
En "Mendoza"21, de 2008, en virtud de una demanda colectiva entablada por la señora Beatriz Mendoza a la que luego adhirieron otras asociaciones civiles, la corte encontró que la política ambiental sostenida por el Estado nacional, la provincia de Buenos Aires y la Ciudad Autónoma de Buenos Aires respecto a la cuenca Matanza-Riachuelo ${ }^{22}$ resultaba violatoria al derecho a disfrutar de un ambiente sano, a tener salud y a mantenerse con vida de todas las personas que habitan sus alrededores.

Por ende, abriéndose paso a través de un proceso sui géneris, resolvió condenar a las demandadas a que -a través de una autoridad de cuenca- ejecute una política de saneamiento y erradicación de empresas contaminantes, partiendo de un plan detallado en el mismo resolutorio. En el considerando $17^{\circ}$ le da forma a dicho plan. Fija como objetivos la mejora en la calidad de vida de los habitantes de la cuenca, la recomposición del ambiente de la misma y la prevención de daños predecibles. Luego detalla con suma precisión las medidas a adoptar, por un lado, para garantizar el acceso a la información pública de todo el proceso y, por el otro, frente a la contaminación industrial, los basurales, la contaminación de márgenes de río, la ausencia de cloacas, etcétera. Para cada etapa ha fijado plazos, cuyo incumplimiento importará -adelanta- la aplicación de una multa diaria en cabeza del presidente de la autoridad de cuenca.

En "F. A. L." 23 , de 2012, la corte afrontó la habitual judicialización de abortos no punibles (en el caso, los habilitados por el inciso $2^{\circ}$ del art. 86 del Código Penal argentino: los de embarazos producidos a partir de violaciones). Entre otras cuestiones, observó que ante pedidos de abortos de ese tipo se da una práctica contra legem, encabezada por los profesionales médicos y convalidada por los agentes del poder judicial, a partir de la cual se imponen obstáculos no considerados en la ley, que en la práctica generan un impedimento a su realización (considerando $19^{\circ}$ ).

Ello es una grave omisión del Estado -reflexionó-, pues este tiene el deber de poner a disposición de quienes soliciten esa clase de abortos todas las condicio-

21 CSJN, "Mendoza Beatriz Silvia y otros c/ Estado Nacional y otros s/ daños y perjuicios (daños derivados de la contaminación ambiental del Río Matanza-Riachuelo)", Fallos: 331:1622, de 8 de julio de 2008.

22 La cuenca Matanza-Riachuelo es la cuenca fluvial más contaminada de Argentina y aparentemente una de las diez más contaminadas del planeta (lo dice el Blacksmith Institute en el informe "The worlds worst 2013: the top ten toxic threat", página 17, que se puede recuperar en: https://www.worstpolluted.org/docs/ TopTenThreats2013.pdf). Tiene una superficie aproximada de dos mil kilómetros cuadrados. Se emplazan en su curso más de cuatro mil establecimientos industriales.

23 CSJN, “F. A. L. s/ medida autosatisfactiva”, Fallos: 335:197, de 13 de marzo de 2012. 
nes sanitarias para hacerlos en virtud de la norma que expresamente los autoriza (considerando $25^{\circ}$ ). Es decir, identificó allí una política estatal (de salud) ausente, pero jurídicamente exigible, en tanto dicha ausencia conllevaba un impedimento fáctico para la realización de los abortos no punibles.

La decisión del tribunal fue exhortar a las autoridades nacionales, provinciales y de la Ciudad Autónoma de Buenos Aires a que implementen protocolos para la concreta atención de ese tipo de abortos con el objeto de remover las barreras fácticas al acceso a los servicios médicos. En particular, detalló, los protocolos deberán contemplar pautas que garanticen la información y la confidencialidad a la solicitante, evitar procedimientos que retrasen demasiado la práctica, articular mecanismos que permitan resolver sin dilaciones las diferencias que pudieran ocasionarse, etcétera (considerando 29\%).

Un mes después de resolver aquella causa, en abril de 2012, la corte dictó una de sus sentencias más notables en lo que a la exigibilidad de los derechos sociales se refiere. Se trata del caso "Q. C., S. Y." 24.

El proceso inició con la demanda interpuesta por una mujer, por derecho propio y en representación de su hija con discapacidad, contra la Ciudad de Buenos Aires, para que el gobierno las incluyera en un programa gubernamental que les permitiera dejar de vivir en la calle. Los subsidios que otorgaba la ciudad para quienes estaban en esa situación eran limitados en el tiempo (un máximo de diez cuotas mensuales) y no alcanzaban a costear una vivienda habitable y accesible para ellas, atendiendo en especial al cuadro que presentaba su niña.

Luego de analizar el sistema de fuentes aplicable al caso, la corte indicó que "la primera característica de esos derechos y deberes es que no son meras declaraciones, sino normas jurídicas operativas con vocación de efectividad" (considerando 90) y que esa operatividad consagra obligaciones a cargo del Estado (considerando 11\%). Para el tribunal son los poderes ejecutivo y legislativo los que deben definir, en primer término, cómo se alcanza dicho objetivo. Sostuvo:

[E]sta Corte no desconoce las facultades que la Constitución le asigna tanto al Poder Ejecutivo como al Poder Legislativo locales, en el ámbito de sus respectivas competencias, para implementar los programas o alternativas destinadas a hacer operativo el derecho a la vivienda y al hábitat adecuado. Es incuestionable que no es función de la jurisdicción determinar qué planes concretos debe desarrollar el gobierno (considerando 110).

24 CSJN, “Q. C., S. Y. C/ Gobierno de la Ciudad de Buenos Aires y otro s/ amparo”, Fallos: 335:452, de 24 de abril de 2012. 
Sin embargo, acto seguido el tribunal hizo otra afirmación que interesa especialmente para este trabajo: que la tercera de las características de los derechos fundamentales que consagran obligaciones de hacer a cargo del Estado "es que están sujetos al control de razonabilidad por parte del Poder Judicial" (considerando $12^{\circ}$ ).

Permítanme que transcriba un pasaje relativamente extenso de la sentencia. Se justifica porque es allí donde la corte detalla con mayor profundidad, en comparación con los precedentes anteriores, su opinión sobre la función del poder judicial en el control de la adecuación de las políticas estatales a los derechos. Dice el tribunal:

Lo razonable en estos casos está relacionado con el principio que "manda desarrollar las libertades y derechos individuales hasta el nivel más alto compatible con su igual distribución entre todos los sujetos que conviven en una sociedad dada, asi como introducir desigualdades excepcionales con la finalidad de maximizar la porción que corresponde al grupo de los menos favorecidos (Rawls, John, 'A Theory of Justice', 1971, Harvard College)". Estos principios de igualdad democrática y de diferencia con finalidad tuitiva de los sectores excluidos deben ser respetados por quienes deciden politicas públicas.

En el campo de las reglas normativas, ello significa que hay una garantía minima del derecho fundamental que constituye una frontera a la discrecionalidad de los poderes públicos. Para que ello sea posible, debe acreditarse una afectación de la garantía, es decir, una amenaza grave para la existencia misma de la persona [...].

La razonabilidad significa entonces que, sin perjuicio de las decisiones politicas discrecionales, los poderes deben atender a las garantías minimas indispensables para que una persona sea considerada como tal en situaciones de extrema vulnerabilidad.

Esta interpretación permite hacer compatible la división de poderes, la discrecionalidad politica del Poder Ejecutivo y del Congreso, con las necesidades minimas de los sectores más desprotegidos cuando éstos piden el auxilio de los jueces (considerando $12^{\circ}$ ).

Sobre el final del voto mayoritario, a modo de conclusión, el tribunal reiteró:

[L]os derechos fundamentales que consagran obligaciones de hacer a cargo del Estado con operatividad derivada, están sujetos al control de razonabilidad por parte del Poder Judicial. Que ello significa que, sin perjuicio de las decisiones politicas discrecionales, los poderes deben atender a las garantías minimas indispensables para que una persona sea considerada como tal en situaciones de extrema vulnerabilidad (considerando 17\%). 
En paralelo a esa línea jurisprudencial, en los casos "ATE” (2013) 25 y "Renatre" $(2015)^{26}$, la CSJN ha reconocido como contenido de los derechos sociales el deber del Estado de garantizarlos progresivamente y, como piso, la prohibición de que retroceda en el nivel de garantía logrado. Para que una política regresiva sea constitucional, sostiene el tribunal citando al Comité de Derechos Económicos, Sociales y Culturales (ONU), debe justificarse plenamente con referencia a la totalidad de los derechos previstos en el Pidesc y en el contexto del aprovechamiento máximo de los recursos de que el Estado disponga (“ATE”, considerando 9).

Con sustento en las tesis jurisprudenciales reseñadas, los tribunales estarían en condiciones de evaluar la corrección constitucional de las políticas adoptadas por la administración, siempre respetando los límites impuestos por una división de poderes en proceso de refundación.

Cada vez que concurran derechos constitucionales fijando objetivos sociales, el Poder Judicial podría “evaluar” la constitucionalidad de las políticas y reputarlas violatorias del marco constitucional si así lo ameritase la situación.

Si bien es cierto que la corte ha negado que los tribunales estén facultados para "evaluar" políticas, afirmando que sólo podría invalidarlas siempre que limitaran derechos, entiendo que esa diferencia es en buena medida retórica, dado que para efectuar esta última operación necesariamente se requiere, como paso previo, realizar una evaluación de los resultados de las políticas en cuestión y valorar los mismos a través del tamiz de los derechos. Entonces, siempre el Poder Judicial estará "evaluando" políticas, pese a que esa evaluación esté limitada al contenido de los derechos.

Retomemos algunos de los pasajes más relevantes de las sentencias mencionadas.

Cuando en un proceso se analiza la constitucionalidad de una política, dice la corte, "lo único que hace el Poder Judicial, en su respectivo ámbito de competencia y con la prudencia debida en cada caso, es tutelar los derechos e invalidar esa política sólo en la medida en que los lesiona. Las políticas tienen un marco constitucional que no pueden exceder, que son las garantías que señala la Constitución y que amparan a todos los habitantes de la Nación" ("Verbitsky", considerando $27^{\circ}$ ).

25 CSJN, “Asociación de Trabajadores del Estado s/ Acción de Inconstitucionalidad”, Fallos: 336:672, de 18 de junio de 2013.

26 CSJN, "Registro Nacional de Trabajadores Rurales y Empleadores c/ Poder Ejecutivo Nacional y otro s/ acción de amparo", Fallos: 338:1347, de 24 de noviembre de 2015. 
Para el cese de una situación irregular violatoria de derechos "puede resultar necesario exigir la adopción [...] de conductas positivas de realizar reformas sistemáticas" ("Gutiérrez", considerando 70).

No debe verse en ello "una intromisión indebida del Poder Judicial cuando lo único que se hace es tender a tutelar derechos, o suplir omisiones en la medida en que dichos derechos puedan estar lesionados" ("Defensor del Pueblo contra Chaco", considerando $3^{\circ}$ ).

Hay una garantía mínima del derecho fundamental que constituye una frontera a la discrecionalidad de los poderes públicos. Sin perjuicio de las decisiones políticas discrecionales, la razonabilidad significa que "los poderes deben atender a las garantías mínimas indispensables para que una persona sea considerada como tal en situaciones de extrema vulnerabilidad" ("Q. S., C. Y.”, considerando 12\%).

Expresa o tácitamente, en los precedentes revistados nos encontramos con esta estructura de razonamiento:

(1) las politicas estatales tienen como límite y objetivo el contenido de los derechos;

(2) en virtud de ello, están supeditadas a la aprobación de un test de constitucionalidad acerca de la razonabilidad de sus avances sobre estos últimos (es decir, hasta qué punto pueden limitarlos y hasta qué punto deben avanzar para garantizarlos);

(3) en caso de desaprobarlo, devendrían inconstitucionales y, por consiguiente, la judicatura tendría la facultad de declarar esa violación como tal (sea por acción o por omisión) y, una vez dado ese paso,

(4) estipular mecanismos para remediar tal situación.

De allí pueden diferenciarse con claridad dos grandes etapas de la decisión judicial sobre políticas estatales (por lo menos bajo el formato diseñado por la corte): una declarativa, en la cual la autoridad judicial expresa su apreciación sobre el apego de una política al marco constitucional ${ }^{27}$, y otra propositiva, en la cual dicha autoridad adopta una decisión acerca de cómo remediar la falta de correlación entre políticas y derechos que hubiera corroborado antes ${ }^{28}$.

27 En Defensor del Pueblo contra Chaco, por ejemplo, cuando corrobora y destaca la corte que la ausencia de políticas violaba derechos sociales de carácter esencial (alimentación, salud). O en Mendoza, cuando observa que la situación de la cuenca Matanza-Riachuelo viola el derecho a un ambiente sano y, a través de dicha violación, el derecho a la salud de las personas que habitan a su alrededor.

28 En Defensor del Pueblo contra Chaco, cuando la corte manda cautelarmente a las autoridades demandadas a que suministren alimentación, agua y transporte. O en Mendoza, cuando dispone la implementación de un plan general de saneamiento e información. 
Una postura de ese tipo acerca de las facultades de control de políticas estatales del poder judicial es pasible de diversas críticas.

En cuanto a su nivel de desarrollo, podría apuntarse que quedan demasiadas preguntas sin responder, en especial relacionadas con el alcance concreto y los límites de las facultades judiciales de revisión de las políticas públicas. La corte no se ha detenido a explicar con detalle cómo debería analizarse el acople entre políticas y derechos, ni qué factores deberían considerarse para justificar, si fuera el caso, la declaración de inconstitucionalidad de las primeras.

Del conjunto de interrogantes que no han sido respondidos son especialmente relevantes los siguientes: ¿cómo determinar cuándo una política lesiona un derecho? ¿Acaso lo hace solo cuando no atiende las garantías mínimas indispensables de las que habla el tribunal? Si así fuera, ¿cómo definir en qué consisten éstas? ¿Debería diferir esa respuesta de acuerdo al derecho involucrado? Por otra parte, ¿en qué medida el poder judicial puede determinar las conductas positivas adoptar para remediar una situación de violación a derechos?

El esquema del test de constitucionalidad que según la corte debe aplicarse a los casos que nos interesan queda relativamente indeterminado al no tener respuestas para esas interrogantes. Podría decirse que esa indeterminación es una consecuencia ineludible de trabajar con derechos constitucionales, que están en sí mismos indeterminados. Sin embargo, creo que podemos trazar aquí una división conceptual. Por un lado, tenemos la metodología para dotar de sentido a los derechos constitucionales, que ocupa buena parte del esfuerzo intelectual de la teoría constitucional contemporánea. Por el otro, tenemos la metodología propia del litigio del acople de las políticas estatales a esos derechos, que si bien supone cierta definición acerca de su contenido, también necesita de otras propias de su intersección con la actividad estatal.

La falta de definición de ambos métodos, el de la interpretación constitucional y el del juicio de razonabilidad aplicado al acople entre derechos y políticas, genera un notable grado de discrecionalidad en cabeza de los jueces, el cual sería conveniente limitar.

Si la nueva integración de la Corte Suprema decidiera continuar con esta línea jurisprudencial, sería un gran paso para la temática que nos ocupa que avanzara en la satisfacción de esas interrogantes que acabo de señalar.

Desde otra óptica, a la postura adoptada por la corte le caben las críticas que suelen hacerse a la intervención judicial en las políticas públicas. Esbozaré sucintamente las tres que entiendo más relevantes. 
Legitimidad democrática. La más potente de las críticas, de cuyo núcleo se desprenden las demás, apunta a la legitimidad democrática del Poder Judicial para controlar las decisiones adoptadas por los poderes electivos, es decir, los que fueron elegidos libremente a través del sufragio (y por ello mismo cuentan, a priori, con mayores credenciales democráticas). A grandes rasgos puede decirse que, según este enfoque, el carácter contramayoritario de aquel poder de Estado lo invalidaría para adoptar decisiones relevantes en cuanto a los rumbos de la vida pública, entre las cuales sin dudas se encuentran las que tienen que ver con la distribución de los recursos fiscales y la impronta del accionar estatal (que da forma a uno u otro modelo de Estado) ${ }^{29}$.

Indeterminación relativa. En conexión con lo anterior, la cuestión se agrava si se repara (como lo he hecho unos párrafos atrás) en que los derechos constitucionales, de acuerdo a su misma estructura normativa, se encuentran relativamente indeterminados, por lo que sus alcances precisos son definidos primordialmente a partir de interpretaciones judiciales. Eso colocaría a la autoridad judicial, según algunos, en una posición demasiado poderosa que, dada su baja legitimidad democrática, no sería aceptable que ocupe en nuestros Estados. Estos asertos son robustecidos por posiciones como las Duncan Kennedy (2010, pp. 29-32), quien sostiene que los jueces suelen adoptar lo que llama comportamiento estratégico al momento de interpretar los materiales jurídicos y decidir sobre su virtualidad respecto a cierto conflicto: ellos adoptan previamente una decisión y luego despliegan los argumentos necesarios para justificarla. El factor que predomina en la elección de la solución dentro del marco fijado por la juridicidad-afirma el autor- es de carácter ideológico y/o psicológico. Ello da lugar a una preocupación bien concreta: que se invaliden decisiones adoptadas mayoritariamente a partir de apreciaciones individuales (quizá arbitrarias, antojadizas) de los jueces.

Capacidad epistémica. Otra importante crítica (que impacta también en la legitimidad de estas intervenciones) radica en la capacidad de la autoridad judicial de conocer acabadamente las características de los conflictos con políticas estatales y las eventuales consecuencias de sus decisiones al respecto. Según esta línea argumental, los actores judiciales carecen de capacitación técnica en materia de gestión, evaluación y control de políticas estatales. Y, además, no tienen la capacidad de conocer con exactitud los efectos que las decisiones respecto a políticas puntuales pudieran surtir en el esquema general del aparato burocrático estatal

29 Un resumen de esta crítica puede encontrarse en Grosman (2008), p. 133. Un estudio exhaustivo sobre la caracterización contramayoritaria del poder judicial en GARGARELLA (2011). 
y la inyección en el mismo de recursos presupuestarios ${ }^{30}$. Esta crítica se hace eco de que la planificación y el diagrama de políticas estatales es algo complejo, que involucra conocimientos de una cantidad de circunstancias mayúsculas, del campo sobre el que se intervendrá, de los actores que lo habitan, y también involucra la necesidad de lograr consensos y cierta capacidad para manejar y canalizar los disensos más relevantes. Ambas carencias terminan -se afirma- por debilitar la legitimidad de la intervención del poder judicial en estas cuestiones, no solo por sus defectos democráticos, sino también porque demostrarían las bajas posibilidades de que se adopten desde ese marco de actuación decisiones eficaces y completamente conscientes.

\section{Algunas alternativas para fortalecer las CAPACIDADES ESTATALES DE CONTROL}

Como vimos, la falta de mecanismos de control dedicados a asegurar la adecuación sustancial entre políticas y derechos puede ser suplida por los tribunales. O eso es lo que la Corte Suprema de Justicia de la Nación argentina sostiene en los precedentes analizados.

Las críticas que han despertado este tipo de posturas pueden recibir matices de acuerdo al grado de intervención que los tribunales pretendan ejercer sobre la conformación y ejecución de las políticas. Se han presentado alternativas que pretenden conciliar las críticas registradas con una mirada robusta de los derechos enfocada en la etapa propositiva de las decisiones. Una de ellas es la propuesta por una justicia dialógica, que plantea colocar a la autoridad judicial en una posición acompasada con los demás poderes del Estado. Según esta postura, y a grandes rasgos, los jueces deberían construir su decisiones a través de un diálogo con las autoridades involucradas, lo cual permitiría diluir las críticas acerca de su legitimidad para intervenir en estos conflictos y su capacidad epistémica para tomar decisiones eficaces ${ }^{31}$.

Las críticas también pueden matizarse en virtud de los mecanismos adoptados para conocer las ramificaciones de la problemática abordada. Puntualmente, se ha hecho notar que si la autoridad judicial adoptase una posición más modesta $y$, en vez de pretender conocer por sí sola las políticas para luego determinar sus

30 Para un detalle de esta crítica, ver Grosman (2008), p. 117.

31 Una descripción de las características generales de la propuesta puede encontrarse en GARGARELLA (2013), así como en Rodríguez (2013). 
configuraciones "correctas" de acuerdo al derecho, se dispusiese a entablar un diálogo con las autoridades de gobierno, podría llegar a apreciaciones más precisas acerca de la problemática que tiene frente a sí (podría conocer, por ejemplo, si determinada posición advertida a gran escala implica un posicionamiento predominante o no) y las alternativas más eficaces disponibles para solucionarlas ${ }^{32}$.

La crítica democrática también puede diluirse en aquellos supuestos en que la intervención del poder judicial termine colocando en agenda ciertas cuestiones relacionadas con violaciones a derechos que de otro modo no habrían logrado serlo. Obsérvese, por ejemplo, cómo la decisión de la CSJN de intervenir en el caso Mendoza (2008) favoreció la visibilidad de las problemáticas ambientales en diversos campos. En el campo del derecho, por un lado, dinamizó discusiones sobre los mecanismos procesales para dirimir cuestiones ambientales, la eficacia de la prueba, etcétera. En el campo de la política, por otro lado, movilizó la jerarquización de los repartimientos encargados de cuestiones ambientales dentro de la estructura estatal, entre otros cambios. Esto, en contextos reactivos para la vigencia de los derechos -especialmente los sociales-, podría dar a los sectores vulnerables una importante herramienta para pujar por su reivindicación, e inclusive podría implicar su incorporación al proceso de decisión y diseño de políticas y dar lugar a la adopción efectiva de una política estatal sobre la cuestión planteada.

No olvidemos que esa crítica recae con mayor fuerza en el ejercicio de "funciones propositivas" por parte del poder judicial y con menor fuerza en las "funciones declarativas". Evidentemente, no es lo mismo declarar que una política viola un derecho que determinar cómo debería diseñarse la política en cuestión para no hacerlo.

Pero más allá de eso, entiendo que una buena manera de fortalecer las capacidades estatales de control es plantear alternativas institucionales que puedan coadyuvar en esa tarea con el control judicial. En ese entendimiento, presentaré algunas propuestas sobre alternativas institucionales que, sin circunscribirse al ámbito del poder judicial, podrían ser capaces de contribuir a la resolución de las situaciones de falta de correlación objeto de este trabajo.

El enfoque de derechos dentro del Congreso. La ley de administración financiera y sistemas de control del sector público nacional, así como hacen sus pares provinciales, le otorga al Congreso un rol crucial en la fijación de la distribución de los recursos públicos y en el control de la ejecución de las respectivas partidas

32 Esa es la actitud que en líneas generales postula la propuesta acerca de la justicia dialógica mencionada en la nota anterior, y parece ser la tesitura adoptada parcialmente en alguno de los fallos de la CSJN citados (por ejemplo, en Verbitsky o, con matices, en Mendoza). 
presupuestarias. En este contexto, sería importante asegurar la incorporación de un enfoque de derechos en los debates parlamentarios donde se estudie dicha distribución a la luz de los compromisos estatales con la vigencia efectiva de los derechos a partir de indicadores de progresividad en su goce y, a la vez, analice los proyectos de ley en torno a sus condiciones institucionales de eficacia (esto es: qué necesitan estos nuevos derechos para hacerse realidad).

La falta de un enfoque de derechos en la producción legislativa tiene consecuencias perniciosas sobre sus posibilidades de lograr vigencia. A modo de ejemplo, se puede traer a colación la Ley No 27.044, por la que el Estado argentino otorgó jerarquía constitucional a la Convención sobre los Derechos de las Personas con Discapacidad. Este instrumento propone un cambio de paradigmas respecto a la capacidad, que altera completamente el modelo de comprensión de la discapacidad, produciendo un desplazamiento desde el paradigma médico rehabilitatorio hacia el paradigma social ${ }^{33}$. Sin embargo, en el debate legislativo de dicha norma estuvo ausente la cuestión de los cambios necesarios en las políticas estatales para adaptar las vetustas instituciones relacionadas con la discapacidad y portadoras del paradigma que la propia Convención vino a desterrar (como la figura de la curatela, felizmente suprimida luego por el nuevo Código Civil y Comercial, o la política de educación especial a partir de la cual los niños con discapacidad se educan separados de los demás niños, lamentablemente aún entre nosotros). La consecuencia de ello es clara: los nuevos derechos con jerarquía constitucional han sido introducidos en un contexto reactivo que resiste y resistirá su desarrollo (el debate en las comisiones y en los plenarios de dicha cámara y la Cámara de Diputados puede consultarse en la página web de ambas cámaras, buscando por el expediente No 0619-S-2012 o por el número de la ley mencionada).

Desde otra perspectiva, también es interesante analizar la función que puede cumplir el Congreso ex post, es decir, de manera reactiva y refractaria a los pronunciamientos judiciales exhortativos. En algunas de las sentencias que hemos estudiado, así como en otras que no han sido insumo de este trabajo, la corte ha recurrido a decisiones de tipo exhortativas, donde pone en conocimiento de organismos públicos cierta situación problemática para que tomen medidas tendientes a solucionarla. Muchas críticas se han dirigido contra esa modalidad de decisión, fundamentalmente por su falta de exigibilidad (los actores del proceso

33 Sobre las características e implicancias de este cambio, ver Silveira y Martocci (2015). 
no podrían exigir el cumplimiento del objeto del exhorto ante la pasividad del organismo receptor).

La posibilidad de que el Congreso de la Nación reciba exhortos por parte del poder judicial, como ha sucedido en algunos casos, abre un capítulo aparte en nuestras reflexiones sobre el rol que ese poder del Estado puede cumplir en el acople entre políticas y derechos. Así como sería auspicioso que el Congreso se detenga a trazar un enfoque de derechos en su producción legislativa, merecerían una especial atención aquellas cuestiones que sean puestas en conocimiento por la autoridad judicial, luego de que la misma hubiera conocido las circunstancias fácticas de un conflicto y determinado que se trata de una situación violatoria de derechos. Es decir, a diferencia del enfoque de derechos ex ante, con las sentencias exhortativas se parte de una situación ya corroborada como contraria al texto constitucional por un órgano jurisdiccional. Por ende, sería recomendable que toda reforma institucional tendiente a consolidar un enfoque de derechos dentro del Congreso parta de establecer un mecanismo de recepción y respuesta rápida de las sentencias de tipo exhortativas que el organismo reciba.

Fortalecimiento de los órganos autónomos. En los órganos autónomos actualmente existentes podemos encontrar otra alternativa valiosa. La Auditoría General de la Nación (AGN) es un ejemplo claro de ello. Con suficientes garantías institucionales para emprender estudios independientes acerca del curso de las políticas y su ligazón con los compromisos cristalizados en los derechos, actualmente se encarga de analizar la legalidad y regularidad financiera del actuar estatal. Reformulando sus funciones, el Estado argentino podría gestar un mecanismo de control sustancial con similares características al creado en el marco de la Organización de los Estados Americanos para analizar los informes remitidos por los Estados firmantes de la Convención Americana de Derechos Humanos ${ }^{34}$.

En el mismo sentido podrían fortalecerse los ministerios públicos y la Defensoría del Pueblo, que si bien no tienen explícitamente como función controlar políticas públicas, tienen atribuciones funcionales que, dado el fenómeno de expansión del campo del derecho, podrían darles un rol relevante que cumplir al respecto. La constitución reformada nos trajo esa novedad al incorporar estas tres figuras que tienen como factor común el hecho de que su órbita de intervención es predominantemente jurisdiccional; es decir, que mayormente actúan

\footnotetext{
34 Me refiero en este caso al "Grupo de Trabajo para el análisis de los informes nacionales previstos en el Protocolo de San Salvador”, creado por la Resolución No 2.262 de la Asamblea General (AG/RES. 2.262, XXXVII-O/07).
} 
promoviendo derechos ante los tribunales de justicia. Las posturas expansivas acerca de las competencias jurisdiccionales para analizar políticas estatales les da la posibilidad ejercer sus funciones garantistas planteando la revisión constitucional de aquellas políticas que presenten contradicciones con la agenda de los derechos. Camino, aquel, que carga con una ventaja diferencial frente a las intervenciones judiciales de carácter individual. A través de un esfuerzo no excesivamente superior, los logros obtenidos por estos organismos en modelos de litigio que busquen la reforma de políticas estatales tendrían efecto expansivo, beneficiando a todas las personas que pudieran resultar afectadas por una política estatal, incluso a aquellas que no hayan podido acceder a sus servicios jurídicos (es decir, al universo de beneficiarios "invisibles").

En Argentina, a nivel nacional, el Ministerio Público está dividido en dos organismos independientes entre sí y respecto de los otros poderes del Estado: el Ministerio Público Fiscal (MPF) y el Ministerio Público de la Defensa (MPD). Ambos comparten la atribución conferida por el artículo 120 de la Constitución Nacional: "tiene[n] por función promover la actuación de la justicia en defensa de la legalidad de los intereses generales de la sociedad". Reformas legislativas relativamente recientes han fortalecido la autonomía funcional y financiera de ambas instituciones: la Ley No 27.148 para el MPF35 y la Ley No 27.149 para el MPD 36 .

La figura del Defensor del Pueblo de la Nación también tiene raigambre constitucional. Está prevista en el artículo 86 del texto fundamental con la misión de "[defender y proteger] los derechos humanos y demás derechos, garantías e intereses tutelados en esta Constitución y las leyes, ante hechos, actos u omisiones

35 Que le da la misión de “[...] velar por la efectiva vigencia de la Constitución Nacional y los instrumentos internacionales de derechos humanos en los que la República sea parte y procurar el acceso a la justicia de todos los habitantes" (art. 1\%). Entre sus funciones en materia no penal, los integrantes del MPF pueden: "Peticionar en las causas en trámite donde esté involucrada la defensa de la legalidad y de los intereses generales de la sociedad, en especial, en los conflictos en los que se encuentren afectados intereses colectivos, un interés y/o una política pública trascendente, normas de orden público y leyes no disponibles por los particulares, el debido proceso, el acceso a la justicia, así como cuando se trate de una manifiesta asimetría entre las partes o estén amenazados o vulnerados los derechos humanos, las garantías constitucionales o la observancia de la Constitución Nacional" (art. 31, inciso b).

36 Que lo define como "[...] una institución de defensa y protección de derechos humanos que garantiza el acceso a la justicia y la asistencia jurídica integral, en casos individuales y colectivos, de acuerdo a los principios, funciones y previsiones establecidas en la presente ley" (art. 1º). Los defensores públicos oficiales tienen dentro de sus funciones "Promover la defensa y protección de los derechos económicos, sociales y culturales mediante acciones judiciales y extrajudiciales, de carácter individual o colectivo” (art. 42, inciso o). 
de la Administración” y de "[controlar el] ejercicio de las funciones administrativas públicas", para lo cual se le asigna expresamente legitimación procesal para iniciar procesos judiciales con aquellos objetos y se lo dota de inmunidad y autonomía.

Si bien el derecho público provincial no ha sido abordado en este trabajo, no puede dejar de señalarse que las figuras que acabo de señalar pueden aparecer disminuidas de acuerdo a la provincia en que pongamos el foco, en especial en aspectos claves como la legitimación activa para demandar. En la provincia de Córdoba, por ejemplo, el Defensor del Pueblo tiene vedado por su ley orgánica "modificar, sustituir o dejar sin efecto decisiones administrativas, ni requerir decisiones de los Tribunales de Justicia” (art. 14 de la Ley No 7.741).

\section{CONCluSiOnES}

Las conclusiones obtenidas a partir de este recorrido pueden sintetizarse del siguiente modo.

El trabajo ha partido de dos presupuestos. Por un lado, que con la reforma constitucional de 1994 se ha producido en Argentina una expansión del campo del derecho de la mano de la ampliación del abanico de derechos con jerarquía constitucional. Por el otro, que esa expansión ha significado la redefinición de los fines y funciones de la organización estatal. El Estado ha pasado a ser concebido como una herramienta primordial para la concreción del contenido de los nuevos derechos. Esto coloca a las políticas estatales en un primer plano, ya que son nada menos que la expresión de la potencia transformadora de la estatalidad que le permite operar sobre la brecha entre los derechos y la realidad.

En la estructura orgánica del Estado argentino, a nivel nacional, no encontramos mecanismos destinados exclusivamente a controlar la adecuación sustancial entre ambos factores: políticas y derechos. Una alternativa frente a dicha necesidad es el control judicial.

Para la Corte Suprema de Justicia argentina, en su integración entre los años 2005 y 2015, toda política está revestida por límites dados por la Constitución y la adecuación a esos límites es controlable judicialmente. Para el tribunal, las políticas tienen un marco constitucional que no pueden exceder, que son las garantías que señala la Constitución y que amparan a todos los habitantes de la nación. Según sostiene, hay una garantía mínima del derecho fundamental que constituye una frontera a la discrecionalidad de los poderes públicos. Sin perjuicio de las decisiones políticas discrecionales, la razonabilidad significa que los poderes 
deben atender a las garantías mínimas indispensables para que una persona sea considerada como tal en situaciones de extrema vulnerabilidad.

La corte, sin embargo, no se ha detenido a explicar con detalle cómo debería analizarse el acople entre políticas y derechos, ni qué factores deberían considerarse para justificar, si fuera el caso, la declaración de inconstitucionalidad de las primeras. Quedan abiertos diversos interrogantes, cuya respuesta sería bueno obtener por parte de la nueva integración del tribunal: ¿cómo determinar cuándo una política lesiona un derecho? ¿Acaso lo hace solo cuando no atiende las garantías mínimas indispensables de las que habla el tribunal? Si así fuera, ¿cómo definir en qué consisten estas? ¿Debería diferir esa respuesta de acuerdo al derecho involucrado? Por otra parte, ¿en qué medida el poder judicial puede determinar las conductas positivas a adoptar para remediar una situación de violación a derechos?

Esa definición sobre la función del poder judicial en el control de políticas públicas también ha recibido otra clase de críticas, relacionadas con la legitimidad de ese poder del Estado para tomar tamañas decisiones, con la indeterminación de los derechos sobre los que se apoya (lo que les otorga un generoso grado de discrecionalidad) y con los obstáculos epistémicos que tienen los tribunales para conocer los efectos de las políticas y los impactos de sus eventuales modificaciones.

La inventiva institucional no tiene por qué limitarse al campo del derecho. Es posible e inclusive deseable desarrollar otras alternativas institucionales que tengan por objeto llenar el vacío institucional del que se dio cuenta desde un enfoque de derechos, como la promoción de un enfoque de derechos dentro del Congreso o la creación y fortalecimiento de órganos autónomos dedicados a ello.

\section{BiBLIOGRAFÍA CITADA}

\section{LIBROS Y ARTÍCULOS}

Abramovich, Víctor (2006): "Los estándares interamericanos de derechos humanos como marco para la formulación y el control de las políticas sociales", en Anuario de Derechos Humanos (No 2), pp. 13-51.

Bourdieu, Pierre (2001): Poder, derecho y clases sociales, segunda edición, (Bilbao, Desclée de Brouwer).

CAPELLA, Juan Ramón (1999): Fruta prohibida. Una aproximación histórico-teorética al estudio del derecho y del Estado, segunda edición, (Madrid, Trotta, 1999).

Comanducci, Paolo (2007). "Constitucionalización y neoconstitucionalismo", en Constitución y teoría del derecho (Ciudad de México, Fontamara). 
CourTIs, Christian (2006): "La prohibición de regresividad en materia de derechos sociales: apuntes introductorios", en C. Courtis (Comp.), Ni un paso atrás: la prohibición de regresividad en materia de derechos sociales (Buenos Aires, Editoriales del Puerto).

Eтchichury, Horacio J. (2013): Igualdad desatada: La exigibilidad de los derechos sociales en la Constitución argentina (Córdoba, Universidad Nacional de Córdoba).

GARGARELla, Roberto (2011): La justicia frente al gobierno: Sobre el carácter contramayoritario del poder judicial (Quito, CEDEC - Corte Constitucional para el Período de Transición de Ecuador).

(2013): "El nuevo constitucionalismo dialógico, frente al sistema de los frenos y contrapesos", en Revista Argentina de Teoría Jurídica (No 14), pp. 1-32.

(2014): La sala de máquinas de la Constitución: Dos siglos de constitucionalismo en América Latina (1810-2010) (Buenos Aires, Katz, 2014).

Grosman, Lucas S. (2008): Escasez e igualdad: Los derechos sociales en la Constitución (Buenos Aires, Libraria, primera edición).

Kennedy, Duncan (2010): Izquierda y derecho: Ensayos de teoría jurídica crítica (Buenos Aires, Siglo XXI Editores).

Repetto, Fabián (2004): “Capacidad estatal: Requisito necesario para una mejor política social en América Latina”. Washington D. C.: Instituto Interamericano para el Desarrollo Social, Serie de Documentos de Trabajo I-52.

Rodríguez Garavito, César (2013): "Activismo dialógico y el impacto de los fallos sobre derechos sociales", en Revista Argentina de Teoría Jurídica (Vol. 14, No 2), pp. 1-27.

Rodríguez Garavito, César; Rodríguez Franco, Diana (2010): Cortes y cambio social: Cómo la Corte Constitucional transformó el desplazamiento forzado en Colombia (Bogotá, Centro de Estudios de Derecho, Justicia y Sociedad, DeJusticia).

SANTOS, Boaventura de Sousa (2003): Crítica de la razón indolente: Contra el desperdicio de la experiencia, (Bilbao, Desclée de Brouwer), Volumen I. (2010): Refundación del Estado en América Latina. Perspectivas desde una epistemología del sur (Lima, Instituto Internacional de Derecho y Sociedad). (2014): Derechos humanos, democracia y desarrollo (Bogotá: Centro de Estudios de Derecho, Justicia y Sociedad, DeJusticia). 
Silveira, Paula E.; Martocci, José M. (2015): "Hacia la vida independiente", en Discapacidad, Justicia y Estado (No 5), pp. 115-137.

Oszlak, Óscar, y O’Donnell, Guillermo (1995): “Estado y políticas estatales en América Latina: Hacia una estrategia de investigación”, en Redes (Vol. 2, No 4), pp. 99-128.

Pérez, Luis E.; Rodríguez Garavito, César; Uprimny, Rodrigo (2007): Los derechos sociales en serio: Hacia un diálogo entre derechos y políticas públicas (Bogotá, Centro de Estudios de Derecho, Justicia y Sociedad, DeJusticia).

UPRIMNY, Rodrigo (2011): "Las transformaciones constitucionales recientes en América Latina: Tendencias y desafíos”, en C. Rodríguez Garavito (coord.), El derecho en América Latina: Un mapa para el pensamiento jurídico del siglo XXI (Buenos Aires, Siglo Veintiuno Editores, primera edición), pp. 109-137.

\section{JURISPRUDENCIA ARGENTINA ${ }^{37}$}

Corte Suprema de Justicia de la Nación (CSJN), "Recurso de hecho deducido por el Centro de Estudios Legales y Sociales en la causa Verbitsky, Horacio s/ habeas corpus", Fallos 328:1146, de 3 de mayo de 2005.

Corte Suprema de Justicia de la Nación (CSJN), "Defensor del Pueblo de la Nación c/ Estado Nacional y otra (Provincia del Chaco) s/ proceso de conocimiento", Fallos 330:4134, de 18 de septiembre de 2007.

Corte Suprema de Justicia de la Nación (CSJN), "Mendoza Beatriz, Silvia y otros c/ Estado Nacional y otros s/ daños y perjuicios (daños derivados de la contaminación ambiental del Río Matanza-Riachuelo)”, Fallos, 331:1622, sentencia definitiva de 8 de julio de 2008.

Corte Suprema de Justicia de la Nación (CSJN), "F., A. L. s/ medida autosatisfactiva", Fallos: 335:197, de 13 de marzo de 2012.

Corte Suprema de Justicia de la Nación (CSJN), "Q. C., S. Y. C/ Gobierno de la Ciudad de Buenos Aires y otro s/ amparo", Fallos: 335:452, de 24 de abril de 2012 .

37 Todas las sentencias aquí indicadas pueden ser consultadas en el portal web de la Secretaría de Jurisprudencia de la Corte Suprema de Justicia argentina (https://sj.csjn.gov.ar/sj/) con los datos consignados en este apartado. 
Corte Suprema de Justicia de la Nación (CSJN), "Asociación de Trabajadores del Estado s/ Acción de Inconstitucionalidad”, Fallos: 336:672, de 18 de junio de 2013.

Corte Suprema de Justicia de la Nación (CSJN), "Recurso de hecho deducido por el Defensor Oficial de Alejandro Gutiérrez en la causa Gutiérrez, Alejandro s/ causa No 11.960", Fallos: 338:68, de 19 de febrero de 2015.

Corte Suprema de Justicia de la Nación (CSJN), "Registro Nacional de Trabajadores Rurales y Empleadores c/ Poder Ejecutivo Nacional y otro s/acción de amparo", Fallos: 338:1347, de 24 de noviembre de 2015.

Corte Suprema de Justicia de la Nación (CSJN), "Viñas, Pablo cl EN - M Justicia y DDHH s/ indemnizaciones - Ley No 24.043 - art. 30", Fallos: 341:570, de 22 de mayo de 2018.

\section{JURISPRUDENCIA LATINOAMERICANA}

Corte Constitucional de Colombia, Sentencia T-025, de 22 de enero de 2004.

\section{NORMAS JURÍDICAS CITADAS}

Ley No 24.156, Administracion Financiera y de los Sistemas de Control del Sector Público Nacional. Sancionada: 30 de septiembre de 1992. Promulgada parcialmente: 26 de octubre de 1992.

Ley No 27.044, Jerarquía Constitucional de la Convención sobre los Derechos de las personas con discapacidad. Sancionada: 19 de noviembre de 2014. Promulgada: 11 de diciembre de 2014. 